\title{
Postpartum Cases Referred to a Tertiary Care Hospital
}

\author{
Himsweta Srivastava ${ }^{1}$, Rashmi ${ }^{2}$, Sneha Shree ${ }^{3}$, Reena Pal ${ }^{4}$ \\ ${ }^{1}$ Department of Obstetrics and Gynaecology, UCMS and Guru Teg Bahadur Hospital, Delhi, India. ${ }^{2}$ Department of \\ Obstetrics and Gynaecology, UCMS and Guru Teg Bahadur Hospital, Delhi, India. ${ }^{3}$ Department of Obstetrics and \\ Gynaecology, UCMS and Guru Teg Bahadur Hospital, Delhi, India. ${ }^{4}$ Department of Obstetrics and Gynaecology, UCMS \\ and Guru Teg Bahadur Hospital, Delhi, India.
}

\section{ABSTRACT}

\section{BACKGROUND}

Maternal morbidity refers to complications that have arisen during pregnancy, delivery or during postpartum period. Monitoring the progress of various interventions depends upon measuring the maternal mortality and morbidity. Referral to a tertiary hospital has been described as one of the criteria for measuring maternal morbidity in low income countries. This paper describes the application of a practical approach to the assessment of the burden of postpartum morbidity by means of postpartum referrals to tertiary centre.

\section{METHODS}

This is a retrospective study conducted in the Department of Obstetrics and Gynaecology, Guru Teg Bahadur Hospital (GTBH), Delhi and included women who required admission and treatment for obstetric complaints during postpartum period.

\section{RESULTS}

The common morbidities among postpartum women for which they sought medical services were postpartum haemorrhage (49\%), puerperal pyrexia/sepsis $(24.2 \%)$, followed by pre-eclampsia /eclampsia (11\%). Haemorrhage accounted for 33\%, puerperal sepsis for $24.2 \%$ and eclampsia/pre-eclampsia for $18.1 \%$ of total maternal deaths.

\section{CONCLUSIONS}

This study highlights the need to focus on the quality of postpartum care. The importance of post-partum care should be emphasized. Efforts to decrease maternal mortality and morbidity should focus on high-risk mothers not only during pregnancy and delivery but also during the postpartum period. Maternal mortality audits should be held, attended by the whole staff involved in the care of pregnant women, particularly in preventable cases and accountability should be discussed to avoid future mishaps.

\section{KEY WORDS}

Postpartum Maternal Morbidity, Maternal Mortality, Tertiary Hospital Admission, Severe Acute Maternal Morbidity, Developing Countries, Postpartum Referrals
Corresponding Author:

Rashmi,

C-24, Arya Nagar Apartments,

Plot No. 91, Patparganj,

Delhi-92, India.

E-mail: rashmi.malik2011@gmail.com

DOI: $10.14260 /$ jemds/2019/741

Financial or Other Competing Interests: None.

How to Cite This Article:

Srivastava H, Rashmi, Shree S, et al. Postpartum cases referred to a tertiary care hospital. J. Evolution Med. Dent. Sci. 2019;8(46):3416-3421, DOI: 


\section{BACKGROUND}

The World Health Organization (WHO) defines the postpartum period, or puerperium, as beginning one hour after the delivery of the placenta and continuing until 6 weeks (42 days) after the birth of the infant. Every year about 287,000 women die of causes related to childbirth of which a staggering 99 percent belong to the developing countries. ${ }^{1}$

Maternal morbidity refers to complications that have arisen during the pregnancy, delivery or postpartum period. Severe acute maternal morbidity (SAMM) has been defined by the WHO as "a woman who nearly died but survived a complication during pregnancy, childbirth, or within 42 days of pregnancy termination through care in health facilities." 2 Of the 136 million women who give birth every year, it has been estimated that about 1.4 million have some form of lifethreatening medical emergencies, 9.5 million undergo other complications, and 20 million have long-term disabilities.13,4,5,6 The risk of maternal mortality is 200 times higher in developing countries than the developed ones.7 Thus, the goal to achieve a $75 \%$ reduction in maternal mortality in all countries by the end of 2015 has been set as a part of Millennium Development Goal. ${ }^{8}$ However, it has been well established now maternal mortality represents only the tip of the iceberg of the much larger issue of maternal morbidity which remains hidden. ${ }^{9}$ Therefore, interest on postpartum maternal morbidity has both developed and developing countries has been seen as an increasing trend. Age, multiparity, associated medical diseases, chronic infections like malaria and nutritional deficiencies such as anaemia are among the major risk factors for postpartum maternal morbidity, others being social factors such as lack of intrapartum or postpartum care, illiteracy, lack of access to medical care, improper use of haematinics, poverty and ignorance. Anaemia in turn, predisposes these women to complications such as postpartum haemorrhage, sepsis, preterm labour and low birth weight and neonatal infections. ${ }^{10}$ The postpartum morbidities include infection, injuries, anaemia, urinary complaints, fistula, genital prolapse, hypertension, haemorrhoids and depression. It has been observed that approximately $15 \%$ of all pregnancies are complicated by preventable conditions. ${ }^{7}$ Despite various interventions on maternal mortality and morbidity at the population level in poor and remote areas, statistics show a negligible improvement. Monitoring the progress of these interventions depends upon measuring the maternal mortality and morbidity. Measuring maternal morbidity is even more difficult due to the absence of standard criteria and lack of population-based data. Further, in many developing countries, health services data on postpartum morbidity is limited and a very small proportion of women have access to supervised deliveries and medical care. Also, underreporting is very common with most deaths and morbidities occurring outside of the health system. Still, referral to tertiary hospital has been described as one of the criteria for measuring maternal morbidity in low income countries. ${ }^{11}$

With this view, this paper describes the application of an inexpensive and practical approach to the assessment of the burden of postpartum morbidity, with a larger aim to monitor trends of such referred cases and identify preventable risk factors and thus, decrease the morbidity in postpartum period.

The objective of the study is to determine the frequency and cause for postpartum admission and to assess the maternal outcome in postpartum period so as to strengthen the postpartum care.

\section{METHODS}

\section{Duration}

The present study was done $1^{\text {st }}$ August 2016 to $31^{\text {st }}$ July 2017, by retrospective collection of records of postpartum women who had been referred and admitted in the Department of Obstetrics and Gynaecology, Guru Teg Bahadur Hospital (GTBH) Delhi.

\section{Study Type and Site}

The present study was a retrospective study, conducted in the department of Obstetrics and Gynaecology, Guru Teg Bahadur Hospital (GTBH), Delhi. GTBH is 1000 bedded tertiary referral Government medical college and hospital; situated in the easternmost part of Delhi. It gets a large number of referrals from maternity homes, primary health centers from rural parts of east Delhi, and also from adjoining states such as Uttar Pradesh. Data regarding maternal mortality was collected from maternal mortality register.

\section{Study Population}

The study comprised of all those women who required admission and treatment in the Department of Obstetrics and Gynaecology for obstetric complaints during post-partum period. For the purpose of this study, the WHO definition of the postpartum period (From delivery until 6 weeks after delivery) was used as the time period for inclusion criteria ${ }^{1}$ We included the postpartum women admitted with postpartum problem, who had delivered at home or at other hospitals after reaching 28 weeks of period of gestation. Women admitted for various non-obstetrical problems were carefully excluded and so were those admitted due to neonatal problems.

\section{Statistical Analysis}

A total of 210 subjects were studied and analyzed during this one-year period. A structured proforma was used to gather the information. Descriptive data were tabulated as absolute figures and percentages.

\section{RESULTS}

Table 1 shows the demographic and obstetrical risk factors in our 210 subjects. Among them, 2.8\% were teenagers, 75.7\% were between $20-29$ years of age, $20.5 \%$ were between 30 39 years and $1 \%$ women were more than 39 years old. Majority of them were from outside the Delhi i.e. 55.2\% and $44.8 \%$ were from Delhi. 34.8\% women were primipara, $28.1 \%$ belonged to parity two, $32.3 \%$ belonged to between parity three to four and $4.8 \%$ had more than five children. Majority (97.6\%) of them were unbooked. 
$58.6 \%$ women had home delivery whereas $26.7 \%$ delivered at private health facility, $13.7 \%$ women had delivered at public health facility and 1\% women delivered on the way to the hospital. 59.1\% deliveries were conducted by untrained birth attendants whereas $40.9 \%$ women were delivered by trained attendants or doctors. Most of the women came to the hospital by self (43\%), 37.6\% were referred by private health facility and $19.5 \%$ were referred by public health facility. Majority of women had vaginal delivery $(89.4 \%)$ and only $10.6 \%$ had a Caesarean section. Indications of Caesarean section have been enlisted in table 1 .

Table 2 outlines the cause for which these postpartum patients required hospital admission. The common morbidities among the postpartum women for which they sought medical services were postpartum haemorrhage (49\%), puerperaI pyrexia/sepsis $(25.6 \%)$, followed by preeclampsia/eclampsia (11\%). Commonest type of postpartum haemorrhage was atonic, seen in $57.2 \%$ followed by traumatic type which accounted for $36.8 \%$ of total PPH cases (Fig. 1). Complications amongst these postpartum women have been enumerated in table 3. Multiple complications such as DIC with anaemia, anaemia with septicaemia and pleural effusion, DIC with shock, ARF with pulmonary oedema, DIC with ARF, HELLP syndrome with pulmonary oedema, septic encephalopathy with anaemia and septic encephalopathy with pulmonary Koch's were also seen and thus enlisted in the table.

\begin{tabular}{|c|c|c|}
\hline Variable & Frequency & Percentage \\
\hline \multicolumn{3}{|l|}{ Age } \\
\hline$<19$ & 6 & 2.8 \\
\hline $20-29$ & 159 & 75.7 \\
\hline $30-39$ & 43 & 20.5 \\
\hline$>40$ & 2 & 1 \\
\hline \multicolumn{3}{|l|}{ Residence } \\
\hline Delhi & 94 & 44.8 \\
\hline Outside Delhi & 116 & 55.2 \\
\hline \multicolumn{3}{|l|}{ Parity } \\
\hline 1 & 73 & 34.8 \\
\hline 2 & 59 & 28.1 \\
\hline $3-4$ & 68 & 32.3 \\
\hline$>=5$ & 10 & 4.8 \\
\hline Booked & 05 & 2.4 \\
\hline Unbooked & 205 & 97.6 \\
\hline \multicolumn{3}{|l|}{ Place of delivery } \\
\hline Home & 122 & 58.6 \\
\hline On the way & 3 & 1 \\
\hline Private health facility & 56 & 26.1 \\
\hline Public health facility & 30 & 13.9 \\
\hline \multicolumn{3}{|l|}{ Mode of delivery } \\
\hline Vaginal Birth & 188 & 89.4 \\
\hline Caesarean section & 22 & 10.6 \\
\hline \multicolumn{3}{|l|}{ Delivery conducted by } \\
\hline Untrained birth attendant & 124 & 59.1 \\
\hline Trained birth attendant/Doctor & 86 & 40.9 \\
\hline \multicolumn{3}{|l|}{ Referral by } \\
\hline Self & 90 & 43 \\
\hline Private health facility & 79 & 37.6 \\
\hline Public health facility & 41 & 19.5 \\
\hline \multicolumn{3}{|l|}{$\begin{array}{c}\text { Indications of Caesarean } \\
\text { section }\end{array}$} \\
\hline Fetal distress & 5 & 2.3 \\
\hline Obstructed labour & 3 & 1.4 \\
\hline $\begin{array}{c}\text { Failed induction/Arrest of } \\
\text { cervical dilatation }\end{array}$ & 3 & 1.4 \\
\hline Antepartum haemorrhage & 2 & 1 \\
\hline Others & 6 & 2.9 \\
\hline Not known & 3 & 1.4 \\
\hline Anaemia* & 174 & 82.9 \\
\hline Mild & 14 & 6.7 \\
\hline Moderate & 63 & 30 \\
\hline Severe & 97 & 46.2 \\
\hline \multicolumn{3}{|c|}{ Table 1. Demographic and Obstetrical Risk Factors $(n=210)$} \\
\hline $\begin{array}{l}\text { *Anaemia: WHO Guideline }(200 \\
\text { Moderate anaemia-Haemoglo } \\
\text { 9-11 g/dL }\end{array}$ & $\begin{array}{l}\text { e anaemia-H } \\
<7 \mathrm{~g} / \mathrm{dL} ; \text { Mild }\end{array}$ & $\begin{array}{l}\text { n level 5-7 g/dL; } \\
\text {-Haemoglobin level }\end{array}$ \\
\hline
\end{tabular}

\begin{tabular}{|c|c|c|}
\hline Variable & Frequency & Percentage \\
\hline Postpartum haemorrhage & 103 & 49.0 \\
\hline Atonic & 40 & 38.8 \\
\hline Traumatic & 38 & 36.8 \\
\hline Retained placenta & 19 & 18.4 \\
\hline Others & 06 & 5.8 \\
\hline Pre-eclampsia & 02 & 1 \\
\hline Eclampsia & 21 & 10 \\
\hline Puerperal pyrexia/sepsis & 51 & 24.2 \\
\hline Anaemia & 13 & 6.2 \\
\hline \multicolumn{3}{|l|}{ Others } \\
\hline Respiratory tract Infection & 10 & 4.8 \\
\hline UTI & 3 & 1.4 \\
\hline ARF & 2 & 1 \\
\hline Gaped episiotomy wound & 2 & 1 \\
\hline DVT & 1 & 0.5 \\
\hline Jaundice & 1 & 0.5 \\
\hline Breast abscess & 1 & 0.5 \\
\hline \multicolumn{3}{|c|}{ Table 2. Causes of Postpartum Morbidity } \\
\hline
\end{tabular}

\begin{tabular}{|c|c|c|}
\hline Maternal Complications & Frequency & Percentage \\
\hline Gaped wound & 3 & 1.4 \\
\hline Pulmonary oedema & 2 & 1 \\
\hline Shock & 13 & 6.2 \\
\hline ARF + Anaemia & 6 & 3.1 \\
\hline DIC + Anaemia & 7 & 3.3 \\
\hline $\begin{array}{l}\text { Pleural effusion+ Anaemia+ Septicaemia } \\
\end{array}$ & 2 & 1 \\
\hline DIC + Shock & 1 & 0.5 \\
\hline ARF + Shock & 1 & 0.5 \\
\hline ARF + Pulmonary oedema & 1 & 0.5 \\
\hline DIC + ARF & 1 & 0.5 \\
\hline HELLP + Pulmonary oedema & 1 & 0.5 \\
\hline Septic encephalopathy + anaemia & 1 & 0.5 \\
\hline Septic encephalopathy+ Pulmonary Koch's & 1 & 0.5 \\
\hline Maternal mortality & 33 & 15.7 \\
\hline Postpartum haemorrhage & 11 & 33.3 \\
\hline Sepsis & 8 & 24.2 \\
\hline Eclampsia/Pre-eclampsia & 6 & 18.2 \\
\hline Anaemia & 4 & 12.1 \\
\hline DIC & 4 & 12.1 \\
\hline Jaundice & 1 & 3.03 \\
\hline \multicolumn{3}{|l|}{ Fetal outcome } \\
\hline IUD & 15 & 7.1 \\
\hline Early neonatal death & 03 & 1.4 \\
\hline
\end{tabular}

\begin{tabular}{|c|c|c|}
\hline Variable & Frequency & Percentage \\
\hline Non-surgical Management & 131 & 62.3 \\
\hline Surgical management & 79 & 37.7 \\
\hline Tear repair & 33 & 15.7 \\
\hline Evacuation of retained products & 19 & 9 \\
\hline MRP & 12 & 5.7 \\
\hline Resuturing of gaped wound & 02 & 1 \\
\hline Hydrostatic reduction & 01 & 0.5 \\
\hline Manual repositioning of uterus & 01 & 0.5 \\
\hline Hematoma drainage & 02 & 1 \\
\hline Balloon tamponade & 01 & 0.5 \\
\hline Exploratory laparotomy + drainage of pus & 02 & 1 \\
\hline Exploratory laparotomy + hysterectomy & 04 & 2 \\
\hline Breast abscess drainage & 01 & 0.5 \\
\hline Blood transfusion & 113 & 53.6 \\
\hline Whole blood/Red cell concentrate & & \\
\hline 1-3 units & 94 & 44.7 \\
\hline 4-6 units & 15 & 7.1 \\
\hline$>6$ units & 4 & 2 \\
\hline Fresh Frozen Plasma & 24 & 11.4 \\
\hline Platelet concentrate & 13 & 6.1 \\
\hline ICU admission & 25 & 12 \\
\hline
\end{tabular}

Table 4. Management in Referred Postpartum Patients $(n=210)$

Of these 210 patients with postpartum morbidity, 33 women $(15.7 \%)$ expired. During the same period (August 2016-July 2017), total maternal deaths were 70. This data denotes that these postpartum women had contributed to $47.1 \%$ of total maternal mortality. Amongst these 210 women, perinatal mortality was $8.5 \%$ (Table 3). Table 4 describes the management in our patients. 79 patients (37.6\%) were managed surgically and $62.3 \%$ underwent nonsurgical management. Genital tract injuries were repaired in $15.7 \%$, evacuation of retained products in $9 \%$, manual 
removal of placenta in $5.7 \%$, exploratory laparotomy and hysterectomy done in 4 patients (1.9\%), laparotomy and drainage of pyoperitoneum was done in 2 patients (1\%). Procedures such as hydrostatic reduction of uterus, manual reposition of uterus, drainage of vulval haematoma, pyometra drainage, breast abscess drainage and balloon tamponade each contributed to $0.5 \%$. A total of 113 women (53.6\%) received blood transfusion, 1-3 units of blood was given in $44.7 \%$ of cases, $4-6$ units blood was given in $7.1 \%$ of cases and more than 6 units of blood was given in 2\% of cases. 25 $(12 \%)$ women required ICU admission for various complications enumerated in table 3.

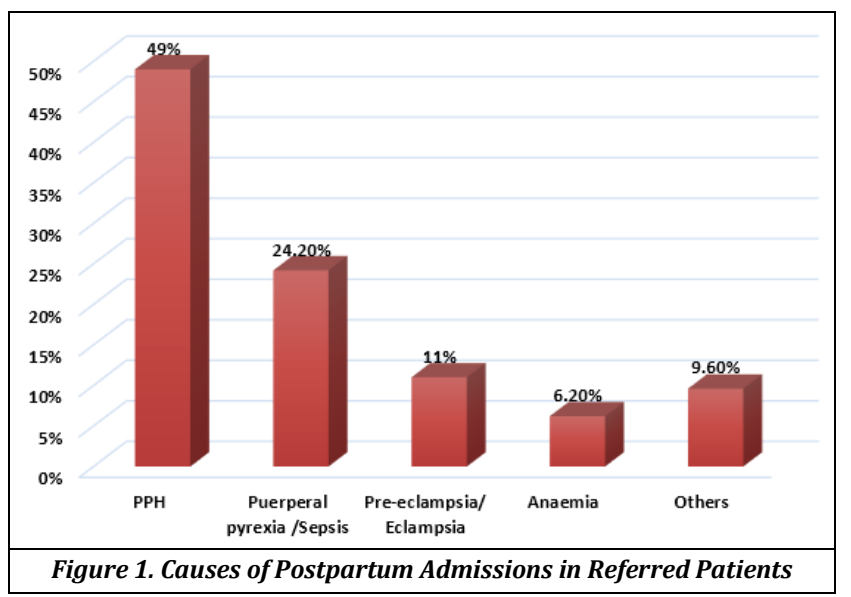

\section{DISCUSSION}

It has been repeatedly observed that in developing countries, a large population of pregnant females do not receive any form of antenatal care; this holds true for postpartum care, as less than one-third females receive any form of postnatal care. ${ }^{12}$ In our study, majority of women (97.6\%) were unbooked. Despite various programs and schemes started by the Government, we still have a large proportion of women who deliver at home in the hands of untrained attendants. In the present study, more than half women (58.6\%) suffered this fate. Being a tertiary referral center, most of the women coming to our hospital have associated risk factors such as anaemia. In the present study, though $82.8 \%$ women were anaemic, only $6.2 \%$ were admitted due to its being direct cause. More than half of these patients i.e. 53.6\% women received blood transfusion. Anaemia also accounted for four maternal deaths in our review. Bibi $\mathrm{S}$ et al found anaemia associated in $100 \%$ of patients requiring postpartum admission. ${ }^{13} \mathrm{Naz}$ et al also found anaemia in $90 \%$ of cases of postpartum admissions. ${ }^{14} \mathrm{~A}$ tertiary hospital review on blood transfusion for primary PPH reported that transfusion within 24 hours of delivery was required in $0.31 \%$ of their patients. ${ }^{15}$ Twenty percent of their patients developed coagulopathy, and $24 \%$ required admission to the intensive care unit.

Causes of hospital admission in postpartum women in our study are in concordance with other studies in the developing countries. Bibi S et al ${ }^{13}$ reported the frequency of obstetric morbidities in a tertiary hospital in Pakistan to be 4 per 100 deliveries comparable with the frequency of 3.3 per 100 deliveries reported from a tertiary hospital of Delhi. ${ }^{16}$ The common obstetric morbidities for which women seek tertiary hospital admission and treatment were postpartum haemorrhage (PPH), pre-eclampsia and sepsis in these studies as well as ours.

Most common direct causes of postpartum admission in our study were PPH (49\%) followed by puerperal sepsis/pyrexia (25.7\%), pre-eclampsia/eclampsia (10.9\%) and severe anaemia (6.2\%). However, non-obstetrical causes contributed to $8.2 \%$ and included respiratory tract infection, jaundice, deep vein thrombosis, breast abscess, etc. (Table 2). PPH was most commonly attributable to maternal morbidity, majority of them being atonic, in accordance to other studies, 17,18 however, traumatic PPH was also a major factor, contributing in $36.8 \%$ of cases, thus making it too an equally important reason for referral.

Bibi $\mathrm{S}$ et al $^{13}$ reported that the most common conditions responsible for life threatening complications were $\mathrm{PPH}$ (50\%), preeclampsia and eclampsia (30\%) and puerperal pyrexia $14 \%$. Anaemia was associated problem in $100 \%$ of cases and maternal mortality rate was $4.8 \%$. These three conditions have been found to be responsible for maternal morbidity and mortality not only in our study but various other studies worldwide. 13,16,19 Similar data has been reported from University Hospital of Damascus, Syria in which the common obstetric morbidities for which women seek tertiary hospital admission and treatment were postpartum haemorrhage (PPH), pre-eclampsia and sepsis. ${ }^{20}$ Data from a study in Zambia differs from that of our region, probably owing to pre-existing conditions and chronic diseases. $^{21}$ In their study, puerperal sepsis was the most frequent diagnosis, accounting for one-third (34.8\%) of all postpartum hospital admissions over the 6-month period. Malaria was the second most common diagnosis accounting for $14.5 \%$ of all cases. Hypertensive disorders accounted for $10.9 \%$. Only three referrals were for postpartum haemorrhage.

It has been reported that sixty percent of maternal mortality occurs in the postpartum period. ${ }^{22}$ Currently, in the developed countries, embolism is the leading cause of the maternal mortality. ${ }^{23}$ However, in the developing countries, PPH continues to be a leading cause, accounting for $25-43 \%$ of the maternal deaths. ${ }^{24,25}$ In this study, maternal mortality occurred in 33 women (15.7\%) which was almost half $(47.1 \%)$ of total maternal mortality of the same year of the hospital. Of these 33 women, direct causes were implicated in three-fourths of cases $(75.8 \%)$ while indirect causes were responsible for $24.2 \%$ of maternal deaths. haemorrhage accounted for $33.3 \%$, puerperal sepsis for $24.2 \%$ and eclampsia/pre-eclampsia for $18.1 \%$ of total maternal deaths. Anaemia contributed in 4 (12.1\%) deaths, so did DIC (12.1\%) and 1 patient succumbed to jaundice (3.03\%) (Fig.2).This data is quite similar to others reported. In another tertiary care hospital review of maternal mortality, direct causes accounted for $72.5 \%$ of maternal deaths whereas $27.5 \%$ of maternal deaths were due to indirect causes. ${ }^{26}$ Haemorrhage (26.66\%), eclampsia (26.66\%), and sepsis (18.33\%) were the major direct causes of maternal deaths. In another study conducted at Madhya Pradesh, obstructed labour was the commonest indication for referral, Haemorrhage and eclampsia were the leading causes of deaths among referred mothers. ${ }^{27}$ Kaur et al reported similar trends in maternal mortality ratio in a tertiary referral hospital. ${ }^{28}$ They found 
that haemorrhage (24.12\%) and sepsis (18.96\%) were the two most common direct cause of deaths followed closely by pregnancy induced hypertension including eclampsia (15.5\%). DIC was the cause of death in $8.6 \%$ of cases and amniotic fluid embolism and pulmonary embolism were the suspected causes in $1.72 \%$ and $5.17 \%$ of cases respectively. Anaemia (12.06\%) contributed to the most common indirect cause of death. Maharlouei et al observed PPH in 35.6\% of recorded causes of death, followed by postpartum sepsis (14.9\%), eclampsia (10.9\%) and pulmonary emboli (6.9\%). ${ }^{29}$

\section{CONCLUSIONS}

This study highlights the need to focus on the quality of postpartum care, which if not more, is equally important as prenatal care. The importance of post-partum care should be emphasized. Efforts to decrease maternal mortality and morbidity should focus on high-risk mothers not only during pregnancy and delivery but also during the postpartum period. Maternal mortality audits should be held, attended by the whole staff involved in the care of pregnant women, particularly in preventable cases and accountability should be discussed to avoid future mishaps. Since postpartum haemorrhage was the most frequent cause of admission in our study and many others, prevention and detection of this condition is of utmost importance. Another extremely important factor, particularly in the developing countries, is an action on the modifiable variables, such as illiteracy and malnutrition, as they contribute indirectly but majorly to the postpartum maternal complications. Reduction in maternal morbidity will, in turn, cause a reduction in maternal mortality. In improving postpartum care, effective programs for health education and iron supplementation are also very important. However, ensuring that all deliveries are conducted by skilled birth attendants is most important so that timely and appropriate identification and management of obstetric complications or referral to centers which can manage the complications can be done.

\section{REFERENCES}

[1] World Health Organization, UNICEF, UNFPA and The World Bank. Trends in Maternal Mortality: 1990-2010. WHO, UNICEF, UNFPA and The World Bank estimates. Geneva: World Health Organization, 2012.

[2] Pattinson R, Say L, Souza JP, et al. WHO maternal death and near-miss classifications. Bull World Health Organ 2009;87(10):734.

[3] Assarag B, Dubourg D, Maaroufi A, et al. Maternal postpartum morbidity in Marrakech: what women feel what doctors diagnose? BMC Pregnancy and Childbirth 2013;13:225.

[4] Ashford L. Hidden suffering: disabilities from pregnancy and childbirth in less developed countries. Measure communication policy brief. Population Reference Bureau, Washington, DC: 2002.
[5] Filippi V, Ronsmans C, Campbell OM, et al. Maternal health in poor countries: the broader context and a call for action. Lancet 2006;368(9546):1535-41.

[6] Say L, Pattinson RC, Gulmezoglu AM. WHO systematic review of maternal morbidity and mortality: the prevalence of severe acute maternal morbidity (near miss). Reproductive Health 2004;1(1):3.

[7] Gupta SD, Khanna A, Gupta R, et al. Maternal mortality ratio and predictors of maternal deaths in selected desert districts in Rajasthan, a community-based survey and case control study. Women's Health 2010;20(1):805 .

[8] United Nations Millennium Declaration Resolution adopted by the General Assembly. 55th Session of the United Nations General Assembly. New York: United Nations, 2000:18. (Accessed on 06.10.2015). http://www.un.org/millennium/declaration/ares552e.p df

[9] Fortney JA, Smith JB. The base of the iceberg: prevalence and perceptions of maternal morbidity in four developing countries. In the maternal morbidity network. Research Triangle Park, NC: Maternal and Neonatal Health Center, Family Health International, 1997:116.

[10] De Benoist B, Mclean E, Egli I, eds. Worldwide prevalence of anaemia 1993-2005: WHO global database on anaemia. World Health Organization, 2008. Accessed on 21.09.2015.

http://whqlibdoc.who.int/publications/2008/97892415 96657_eng.pdf.

[11] Ronsmans C. Severe acute maternal morbidity in low income countries. Best Prac Res Clin Obstet Gynaecol 2009;23(3):305-16.

[12] Mathai M. Safe motherhood by AD 3000? Natl Med J India 1999;12(6):251-3.

[13] Bibi S, Ghaffar S, Memon S, et al. Severe acute maternal morbidity (SAMM) in postpartum period requiring tertiary Hospital care. Iran J Reprod Med 2012;10(2):8792.

[14] Naz H, Sarwar I, Fawad A, et al. Maternal morbidity and mortality due to primary PPH--experience at Ayub Teaching Hospital Abbottabad. J Ayub Med Coll Abbottabad 2008;20(2):59-65.

[15] Balki M, Dhumne S, Kasodekar S, et al. Blood transfusion for primary postpartum haemorrhage: a tertiary care hospital review. J Obstet Gynaecol Can 2008;30(11):1002-7.

[16] Chhabra P, Guleria K, Saini NK, et al. Pattern of severe maternal morbidity in a tertiary hospital of Delhi, India: a pilot study. Trop Doct 2008;38(4):201-4.

[17] Ronsmans C, Graham WJ, Lancet Maternal Survival Series Steering Group. Maternal mortality: who, when, where and why. Lancet 2006;368(9542):1189-200.

[18] Henry A, Birch MR, Sullivan EA, et al. Primary postpartum haemorrhage in an Australian tertiary hospital: a case-control study. Aust N Z J Obstet Gynaecol 2005;45(3):233-6.

[19] Khan KS, Wojdyla D, Say L, et al. WHO analysis of causes of maternal death: a systematic review. Lancet 2006;367(9516):1066-74. 
[20] Almerie Y, Almerie MQ, Matar HE, et al. Obstetric near miss and maternal mortality in maternity university hospital, Damascus, Syria: a retrospective study. BMC Pregnancy and Childbirth 2010;10:65.

[21] Vallely L, Ahmed Y, Murray SF. Postpartum maternal morbidity requiring hospital admission in Lusaka, Zambia - a descriptive study. BMC Pregnancy and Childbirth 2005;5:1.

[22] Li XF, Fortney JA, Kotelchuck M, et al. The postpartum period: the key to maternal mortality. Int J Gynecol Obstet 1996;54(1):1-10.

[23] The Department of Health. Why mothers die. Report on Confidential Enquiries into Maternal Deaths in the United Kingdom 1994-1996. Department of Health (UK): London, 1998.

[24] Tuncer RA, Erkaya S, Siphai T, et al. Maternal mortality in a maternal hospital in Turkey. Acta Obstet Gynecol Scand 1995;74(8):604-6.
[25] Al-Meshari A, Chattopadhyay SK, Younes B, et al. Trends in maternal mortality in Saudi Arabia. Int J Gynecol Obstet 1996;52(1):25-32.

[26] Murthy BK, Murthy MB, Prabhu PM. Maternal Mortality in a tertiary care hospital: a 10-year review. Int J Prev Med 2013;4(1):105-9.

[27] Chaturvedi S, Randive B, Diwan V, et al. Quality of obstetric referral services in India's JSY cash transfer programme for Institutional births: a study from Madhya Pradesh Province. PLoS One 2014;9(5):e96773.

[28] Kaur H, Kaur S, Singh S. Trends in maternal mortality ratio in a tertiary referral hospital and the effects of various maternity schemes on. J of Family \& Reproductive Health 2015;9(2):89-92.

[29] Maharlouei N, Zakeri Z, Mazloomi E, et al. Maternal mortality rate in Fars Province: trends and associated factors in a community-based survey. Arch Iran Med 2012;15(1):14-7. 